\title{
Effects of propiconazole on rice growth and gene expression in response to nitrogen and phosphorus deficiencies
}

\author{
Kewalee Jantapo ${ }^{\mathrm{a}, \mathrm{b}}$, Sompop Pinit ${ }^{\mathrm{a}, \mathrm{b}}$, Lili Zhou ${ }^{\mathrm{c}}$, Wenfei Wang ${ }^{\mathrm{c}}$, Juthamas Chaiwanon ${ }^{\mathrm{b}, *}$ \\ ${ }^{a}$ Program in Biotechnology, Faculty of Science, Chulalongkorn University, Bangkok 10330 Thailand \\ b Center of Excellence in Environment and Plant Physiology, Department of Botany, Faculty of Science, \\ Chulalongkorn University, Bangkok 10330 Thailand \\ ${ }^{c}$ Fujian Provincial Key Laboratory of Agroecological Processing and Safety Monitoring, College of Life \\ Sciences, Fujian Agriculture and Forestry University (FAFU), Fuzhou 350002 China
}

*Corresponding author, e-mail: juthamas.c@chula.ac.th

Received 10 Nov 2020

Accepted 17 May 2021

\begin{abstract}
Nitrogen $(\mathrm{N})$ and phosphorus $(\mathrm{P})$ are essential macronutrients required for plant growth and development. Under $\mathrm{N}$ and inorganic phosphate $(\mathrm{Pi})$ deficiencies, plants undergo adaptation at physiological, morphological, and transcriptional levels via modulation of endogenous signals, such as phytohormones, in an attempt to increase nutrient acquisition from the environment. Biosynthesis of brassinosteroid (BR), a class of plant hormones, has been shown to be crucial in nutrient deficiency responses in the plant model Arabidopsis. In this study, the responses of rice (Oryza sativa L.) to $\mathrm{N}$ and Pi deficiencies were investigated using rice seedlings grown in the presence and absence of a BR biosynthesis inhibitor, propiconazole (PPZ). Transcript levels of BR biosynthesis genes were induced by $\mathrm{N}$ and $\mathrm{Pi}$ deficiencies. PPZ-treated plants showed retarded growth in both sufficient and deficient conditions. Besides, gene expression of $\mathrm{N}$ - and Pi-deficiency-responsive genes was also attenuated by PPZ treatments. These results suggest that inhibition of BR biosynthesis by PPZ could restrain plant growth and adaptation in response to both $\mathrm{N}$ and $\mathrm{Pi}$ deficiencies.
\end{abstract}

KEYWORDS: nitrogen deficiency, phosphorus deficiency, propiconazole, rice

\section{INTRODUCTION}

Nitrogen $(\mathrm{N})$ and phosphorus $(\mathrm{P})$ are two macronutrients required for plant growth and development, and often the major limiting factors in most agricultural system. Deficiencies in $\mathrm{N}$ and inorganic phosphate (Pi) severely affect many physiological processes, including photosynthesis, carbon and nitrogen metabolism, and plant hormone metabolism, leading to reduction in growth, biomass, and yields $[1,2]$. Plants have evolved diverse mechanisms to sense the availability of nutrients in the soil and undergo adaptation at morphological, physiological, and transcriptional levels to cope with the unfavorable conditions [3]. $\mathrm{N}$ and Pi deficiencies have been reported to increase root-shoot biomass ratio and alter root system architecture, allowing plants to explore their surrounding soil and increase nutrient uptake efficiency $[4,5]$.

Plant hormones serve as an important endogenous signal to control plant growth and development in response to nutrient availability and fa- cilitate communication of nutrient status at systemic levels [6]. Brassinosteroid (BR) is a class of growth-promoting plant hormones that regulates diverse physiological processes, including photomorphogenesis, root growth and development, plant defense, and reproductive development [7]. Recent studies have revealed roles of BR in abiotic stresses, such as salinity, drought, and $\mathrm{N}$ and Pi deficiencies $[8,9]$. Under mild $\mathrm{N}$ deficiency, expression of BR biosynthesis genes is up-regulated on Arabidopsis roots, contributing to low N-mediated root elongation as a foraging adaptation to explore more soil volume [10]. Overexpression of a BR biosynthesis enzyme DWARF1 (DWF1) improves plant growth and overall $\mathrm{N}$ accumulation in Arabidopsis [10]. A proteomic study in rapeseed roots also found that DWF1 is enriched by N deficiency, suggesting that the roles of BR biosynthesis in $\mathrm{N}$ deficiency responses are likely conserved across plant species [11]. Under Pi deficiency, BR biosynthesis has been shown to be down-regulated on root elongation in Arabidopsis [12]. Recently, several works 
have shown roles of $\mathrm{BR}$ biosynthesis in $\mathrm{N}$ and $\mathrm{Pi}$ deficiencies in rice. $\mathrm{NH}_{4}^{+}$promotes $\mathrm{BR}$ biosynthesis via miR444-MADS box-OsBRD1 signaling cascade, leading to $\mathrm{NH}_{4}^{+}$-triggered root elongation inhibition [13]. BR biosynthesis or signaling mutants attenuated Pi deficiency-induced leaf inclination by compromising expression of BU1, a BR-induced gene regulating cell elongation of lamina joint in rice [14].

The use of chemical inhibitors to inhibit plant hormone biosynthesis has played significant roles in the advancement of plant hormone research, especially when responsible mutants are not available. Several triazole compounds have been shown to inhibit cytochrome P450 monooxygenase enzymes that catalyze biosynthesis pathways of plant hormones. Paclobutrazole and uniconazole are wellknown plant growth regulators that inhibit gibberellin biosynthesis and are used to alleviate plant abiotic stress [15]. Propiconazole (PPZ) is a specific BR biosynthesis inhibitor that binds CYP90D1 enzyme in the BR biosynthesis pathway [16], resulting in reduced endogenous BR levels and signaling activities [17]. PPZ treatment has been shown to reduce plant height, root length, and biomass, similar to BR mutants, in several plant species including Arabidopsis, soybean, maize, and Brachypodium [17-20].

In agriculture, PPZ application is one of the most widely used fungicides in many crop plants [21]. Highly repeated applications lead to PPZ contaminations, which have been reported in soils and water sources [22], as well as topsoil of paddy rice field [23]. In this study, we investigated effects of $\mathrm{N}$ and Pi deficiency stresses on expression of $\mathrm{BR}$ biosynthesis genes in rice seedlings and effects of PPZ application on $\mathrm{N}$ and Pi deficiency responses by evaluating plant growth, mineral concentrations, as well as expression of genes known to be regulated by $\mathrm{N}$ and Pi deficiencies.

\section{MATERIALS AND METHODS}

\section{Plant materials and growth conditions}

Seeds of rice (Oryza sativa L.) cultivar Zhonghua 11 were sterilized with $3 \% \mathrm{H}_{2} \mathrm{O}_{2}$ overnight and rinsed three times with distilled water. The sterilized seeds were soaked in distilled water and kept in the dark at $30^{\circ} \mathrm{C}$ for 2 days before transferring to a hydroponic condition using Yoshida's nutrient solution (full-strength under sufficient conditions: $1.427 \mathrm{mM} \mathrm{NH}_{4} \mathrm{NO}_{3}, 0.323 \mathrm{mM} \mathrm{NaH} \mathrm{PO}_{4}, 0.512$ $\mathrm{mM} \mathrm{K} \mathrm{SO}_{4}, 0.998 \mathrm{mM} \mathrm{CaCl}_{2}, 1.643 \mathrm{mM} \mathrm{MgSO}_{4}$,
$0.009 \mathrm{mM} \mathrm{MnCl}, 0.075 \mu \mathrm{M}\left(\mathrm{NH}_{4}\right)_{6} \mathrm{Mo}_{7} \mathrm{O}_{24}, 0.019$ $\mathrm{mM} \mathrm{H}_{3} \mathrm{BO}_{3}, 0.152 \mu \mathrm{M} \mathrm{ZnSO}{ }_{4}, 0.155 \mu \mathrm{M} \mathrm{CuSO}_{4}$, and $0.036 \mu \mathrm{M}$ Fe-EDTA) [24]. Germinated seeds were transferred to a net floating on half-strength Yoshida's nutrient solution in the absence and presence of $10 \mu \mathrm{M}$ PPZ for 4 days. Then, uniform seedlings were selected and transferred to fullstrength Yoshida's nutrient solution under sufficient conditions and $\mathrm{N}$-deficient $\left(0.014 \mathrm{mM} \mathrm{NH}_{4} \mathrm{NO}_{3}\right)$ or Pi-deficient $\left(0.003 \mathrm{mM} \mathrm{NaH}_{2} \mathrm{PO}_{4}\right)$ conditions in the absence and presence of $10 \mu \mathrm{M}$ PPZ. The nutrient solutions were renewed every 2 days. All seedlings were grown in a growth room controlled at $30^{\circ} \mathrm{C}$ under $16 \mathrm{~h}$ light and $8 \mathrm{~h}$ dark cycle.

After 10 days of treatments, plant samples were harvested for biomass, $\mathrm{N}$ and $\mathrm{P}$ contents, and gene expression analyses. Three biological replicates were used in all experiments.

\section{Measurements of biomass and total $\mathrm{N}$ and $\mathrm{P}$ contents}

Plant biomass was measured in terms of dry weight and plant height. To measure plant dry weight, root and shoot samples were dried at $70^{\circ} \mathrm{C}$ until a constant weight was recorded. To determine total $\mathrm{N}$ and $\mathrm{P}$ contents, dry root and shoot samples were digested with concentrated $\mathrm{H}_{2} \mathrm{SO}_{4}$, followed by addition of $\mathrm{H}_{2} \mathrm{O}_{2}$ in block digestion machine. The digested solution was completed volume with deionized water. $\mathrm{N}$ and $\mathrm{P}$ concentrations were determined by continuous flow analyzer (Skalar Analytic B.V., Netherlands).

\section{Gene expression analysis}

After treatment, roots and shoots were separated and immediately frozen in liquid nitrogen. Total RNA was extracted from whole root and whole shoots tissues using RNAprep Pure Kit (For Plant) (TIANGEN, China). For each sample, $1 \mu \mathrm{g}$ of total RNA was treated with DNase to eliminate genomic DNA contamination, and first-strand cDNA was synthesized using PrimeScript ${ }^{\mathrm{TM}}$ RT reagent kit with gDNA Eraser (TaKaRa, China) according to the manufacturer's protocol. The cDNA templates were used to quantify target gene expression level by quantitative RT-PCR (qRT-PCR) analysis using gene specific primers listed in Table S1. qRT-PCR was performed on QuantStudio ${ }^{\mathrm{TM}} 6$ Flex Real-Time PCR System using SYBR ${ }^{\circledR}$ Premix Ex Tag ${ }^{\mathrm{TM}}$ (TaKaRa, China). The following thermal profile was used for PCR amplification: initial denaturation at $95^{\circ} \mathrm{C}$ for $30 \mathrm{~s}$, followed by 40 cycles of PCR at $95^{\circ} \mathrm{C}$ for $5 \mathrm{~s}$ and at $60^{\circ} \mathrm{C}$ for $34 \mathrm{~s}$. Melt curve analysis was performed 
to confirm the specificity of the reactions. OsACTIN1 was used as internal control for normalizing gene expression. The relative expression level was calculated by $2^{-\Delta \Delta C t}$ method. The analysis includes three biological replicates, 12 plants per replicate.

\section{STATISTICAL ANALYSIS}

Means and standard errors (SE) were calculated and analyzed by one-way analysis of variance (ANOVA). Mean comparison was calculated according to Duncan's multiple range test (DMRT) using IBM SPSS statistics 20 .

\section{RESULTS AND DISCUSSION}

\section{Expression analysis of BR biosynthesis genes}

To determine whether $\mathrm{N}$ and $\mathrm{Pi}$ deficiencies affect expression levels of BR biosynthesis genes (OsDWF4, OsD2, and OsCYP85A1), total RNAs from shoots and roots of rice seedlings grown under $\mathrm{N}$ deficient, Pi-deficient, or sufficient (control) conditions were harvested and determined transcript levels by quantitative RT-PCR. The results showed that $\mathrm{N}$ deficiency strongly induced OsDWF4 in the roots ( 6 fold compared with the control) (Fig. 1a), consistent with a previous report in Arabidopsis roots [9]. In addition, OsDWF4 and OsD2 were also induced by $\mathrm{N}$ deficiency in the shoots (Fig. 1b). Pi deficiency promoted the expressions of OsDWF4, OsD2, and OsCYP85A1 in the shoots, but not in the roots (Fig. 1ab). These results suggest that both $\mathrm{N}$ and $\mathrm{Pi}$ deficiencies induced expressions of BR biosynthesis genes, but different BR biosynthesis genes might show varied tissue-specific regulation by nutrient status.

\section{Effect of PPZ on plant growth under $\mathrm{N}$ and $\mathrm{Pi}$ deficiencies}

To investigate whether inhibition of BR biosynthesis by exogenous PPZ treatment affects $\mathrm{N}$ and Pi deficiency responses in rice, growth phenotypes of rice seedlings grown in the presence or absence of PPZ under nutrient-sufficient conditions were evaluated. Compared with PPZ-untreated controls, PPZ-treated plants showed significant reduction in root biomass, shoot biomass, and plant height by 49.4\%, 68.1\%, and 76.3\%, respectively (Fig. 2). Moreover, the PPZ-treated plants displayed several phenotypes common to BR-deficient or signaling mutants, including dwarf shoots, short roots, and dark green leaves $[18,25,26]$. The reduction in growth observed in this study is likely due to reduced endogenous BR levels by PPZ inhibiting the
BR biosynthesis enzymes $[18,27]$. Transcript levels of the BR biosynthesis genes (OsDWF4, OsD2, and OsCYP85A1), which are feedback-regulated by the BR signaling pathway [28], showed significant upregulation (Fig. 1cd). In spite of the upregulation of the transcripts, endogenous $\mathrm{BR}$ levels remain low because PPZ binds to CYP90D1 enzyme in the BR biosynthesis pathway and blocks the activities [16]. Thus, the upregulation of the BR biosynthesis genes supported that endogenous BR levels in the PPZtreated plants are blocked, which is consistent with previous reports [29].

In the absence of PPZ, $\mathrm{N}$ deficiency reduced root biomass $(-31.4 \%)$, shoot biomass $(-59.2 \%)$, and plant height $(-28.3 \%)$, while Pi deficiency reduced shoot biomass $(-5.6 \%)$ and plant height $(-10.0 \%)$ but increased root biomass $(+17.6 \%)$ when compared with sufficient condition (Fig. 2). Moreover, when plants were N-deficient, PPZ treatment reduced root biomass, shoot biomass, and plant height $(-26.6 \%,-55.7 \%$, and $-72.5 \%$, respectively), when compared with PPZ-untreated plants. Similarly, when plants were Pi-deficient, PPZ treatment reduced root biomass, shoot biomass, and plant height $(-57.3 \%,-68.0 \%$, and $-72.9 \%$, respectively). Thus, the results showed that PPZtreated plants showed similar growth retardation under sufficient, $\mathrm{N}$-deficient, and Pi-deficient conditions, except reduced degrees of root biomass reduction was found under $\mathrm{N}$-deficient condition. In $\mathrm{N}$ deficient plants, PPZ treatment did not reduce root growth much further than the effect of $\mathrm{N}$ deficiency.

Our results demonstrated that PPZ treatment reduced root adaptation to $\mathrm{N}$ and Pi deficiencies. Previous studies have shown that application of BR biosynthesis inhibitor, brassinazole, suppressed root elongation in low N-treated Arabidopsis [10] and inhibited root formation in low Pi-treated lupin (Lupinus albus L.) [30].

\section{Effects of PPZ on total $\mathrm{N}$ and $\mathrm{P}$ contents in tissues}

Effects of PPZ application on $\mathrm{N}$ and Pi acquisition or accumulations in plant tissues were investigated by measuring total $\mathrm{N}$ and $\mathrm{P}$ contents in rice seedlings. $\mathrm{N}$ and Pi deficiency treatments similarly reduced total $\mathrm{N}$ and $\mathrm{P}$ contents in the PPZ-treated and the PPZ-untreated plants. Interestingly, the PPZtreated plants had higher total $\mathrm{N}$ and $\mathrm{P}$ contents than the PPZ-untreated plants under both sufficient and deficient conditions (Fig. 3). This may be a consequence of smaller cell size and greater cell density of PPZ-treated plants. In agreement with a 
a

Root

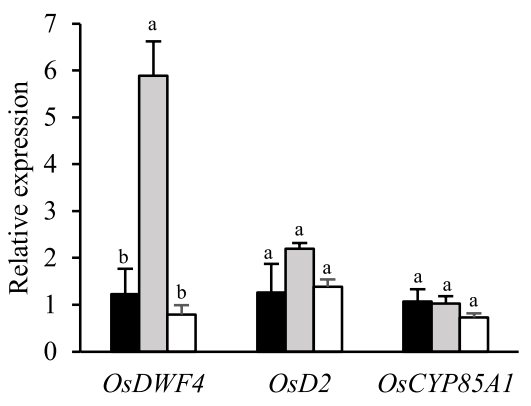

$\mathrm{C}$

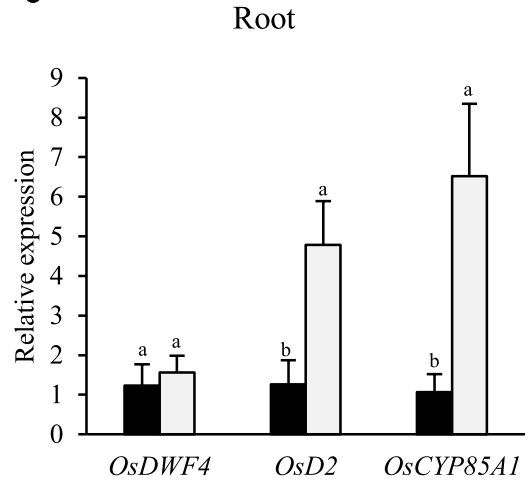

b

Shoot

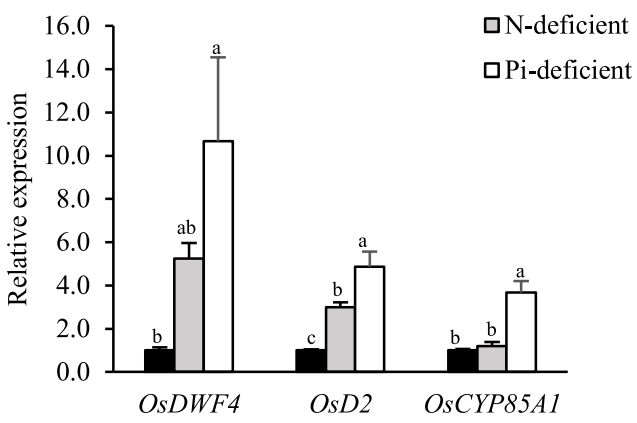

d

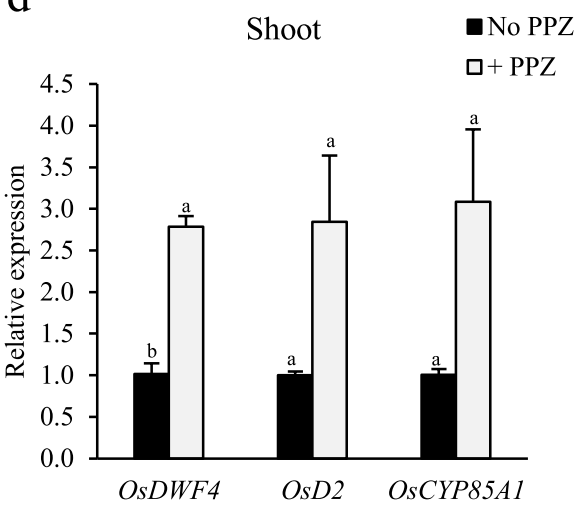

Fig. 1 Gene expression analyses of BR biosynthesis genes in roots $(a, c)$ and shoots $(b, d)$ of rice seedlings. Effects of nutrient deficiency $(\mathrm{a}, \mathrm{b})$ : seedlings were grown under sufficient or N-deficient or Pi-deficient conditions. Effects of PPZ treatments $(c, d)$ : seedlings were grown in nutrient sufficient conditions in the absence or presence of PPZ treatment. Relative expression levels were normalized with OsACTIN. Data are means $\pm \operatorname{SE}(n=3)$. Different letters indicate significant differences $(p<0.05)$ according to Duncan's multiple range test (DMRT).

a

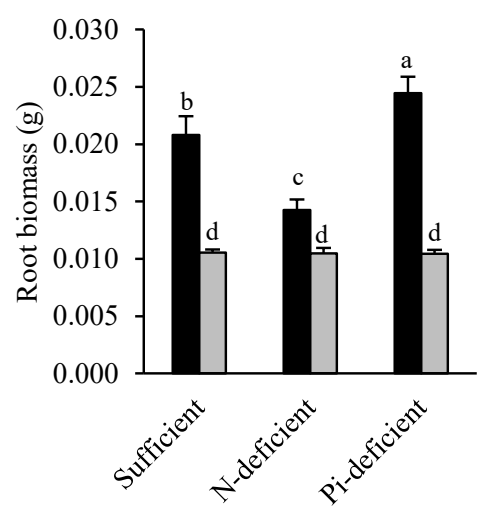

$\mathrm{b}$

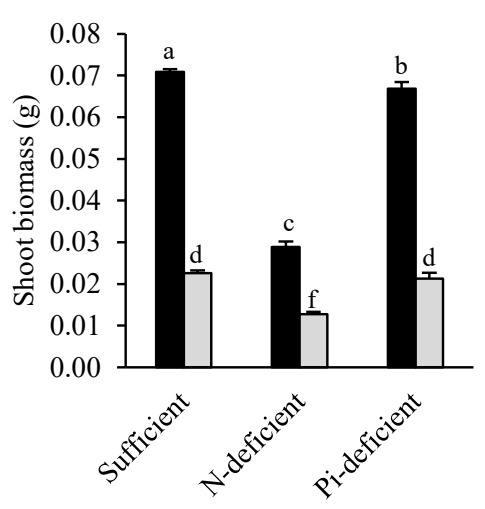

$\mathrm{C}$

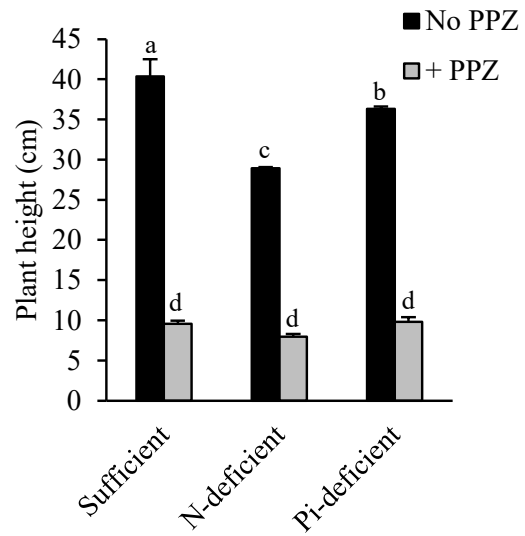

Fig. 2 Effects of PPZ on growth of rice seedlings grown under sufficient, N-deficient, or Pi-deficient condition showing quantification of root biomass (a), shoot biomass (b), and plant height (c). Data are means \pm SE $(n=3)$. Different letters indicate significant differences $(p<0.05)$ according to Duncan's multiple range test (DMRT). 
a

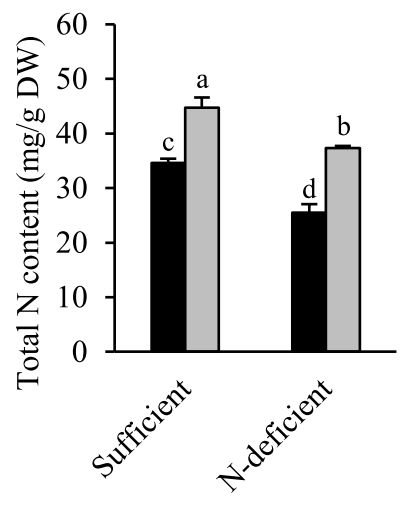

C

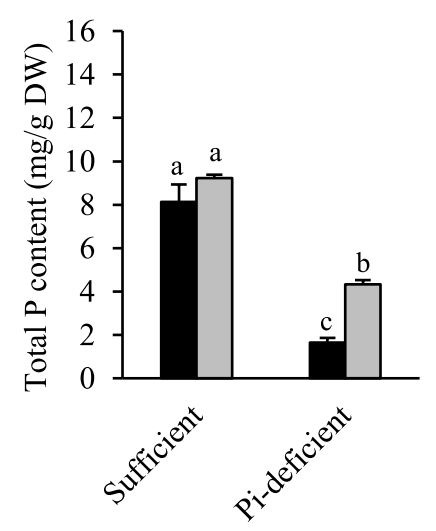

b

Shoot
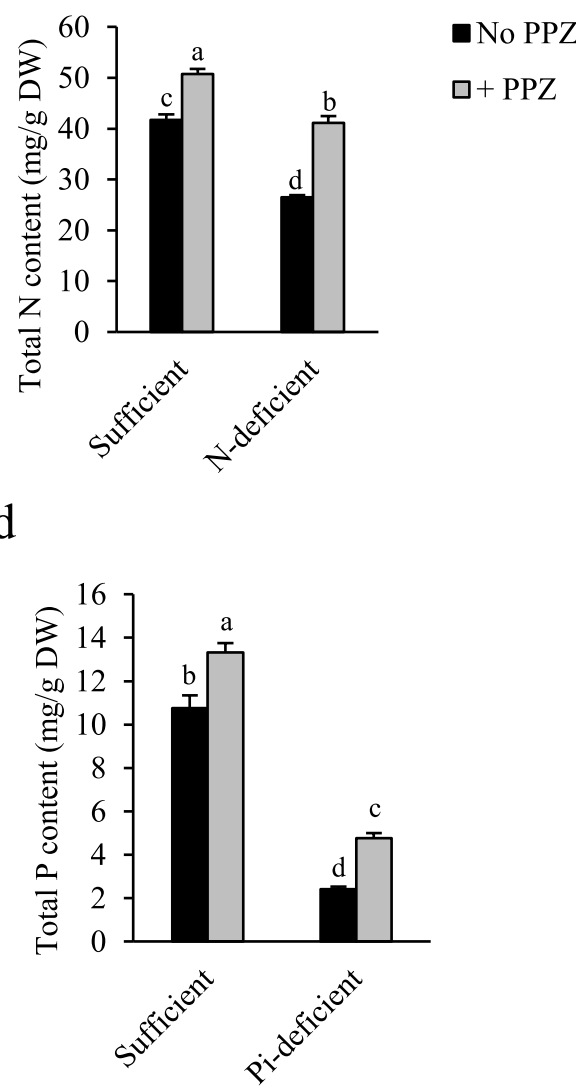

Fig. 3 Effects of PPZ on total N and P contents of rice seedlings grown under sufficient or deficient condition. Total $\mathrm{N}$ contents (mg/g dry weight): in roots (a) and shoots (b) of rice seedlings grown in the sufficient or N-deficient condition. Total P contents (mg/g dry weight): in roots (c) and shoots (d) of rice seedlings grown in the sufficient or Pi-deficient condition. Data are means \pm SE $(n=3)$. Different letters indicate significant differences $(p<0.05)$ according to Duncan's multiple range test (DMRT).

previous study, PPZ-treated plants increased chlorophyll content in leaves, which is likely due to the specific inhibition of cell elongation [31]. However, when total $\mathrm{N}$ or $\mathrm{P}$ accumulations per plant were considered instead of per $\mathrm{g}$ dry weight, PPZ-treated plants had lower total $\mathrm{N}$ and $\mathrm{P}$ contents due to the small shoot biomass (data not shown), similar to previous reports in BR mutants [10].

PPZ treatment reduced growth rates of seedlings (Fig. 2), which may lead to a reduction in nutrient demand compared with the untreated plants. However, both $\mathrm{N}$ and Pi deficiencies led to similar reduction of total $\mathrm{N}$ and $\mathrm{P}$ contents when compared with sufficient conditions (Fig. 3), indicating that the PPZ-treated plants also encountered similar nutrient starvation. Regarding mineral contents in growth-retarded plants, a previous study has shown that under Fe-sufficient conditions, the BR biosynthesis rice mutant (d2-1) showed increased Fe concentrations, but no differences in $\mathrm{Mg}$ and $\mathrm{K}$ concentrations were found when compared with wild-type plants, suggesting that the effect of plant hormone deficiency is specific to Fe and not due to reduced nutrient demand of growth-retarded plants [32].

\section{Expression analyses of genes related to $\mathrm{N}$ and $\mathrm{Pi}$ deficiencies}

Under $\mathrm{N}$-deficient conditions, $\mathrm{N}$ signaling has been shown to induce expressions of many genes related to $\mathrm{N}$ uptake and metabolism, such as nitrate transporters OsNRT2.1 and OsNRT1.1, an ammonium transporter OsAMT1.1, and N-assimilating enzymes OsGS1.1 and OsNADH-GOGAT1 [33]. To determine 
a

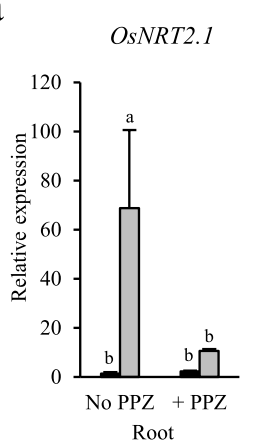

b

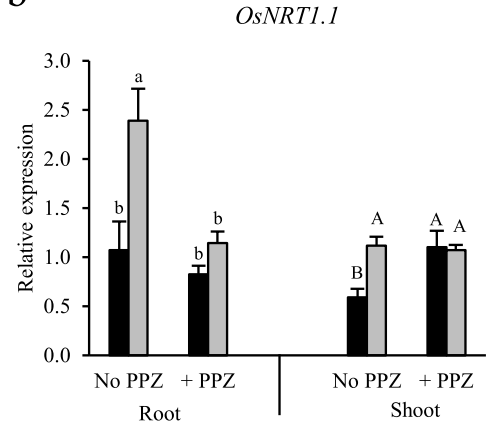

$\mathrm{C}$
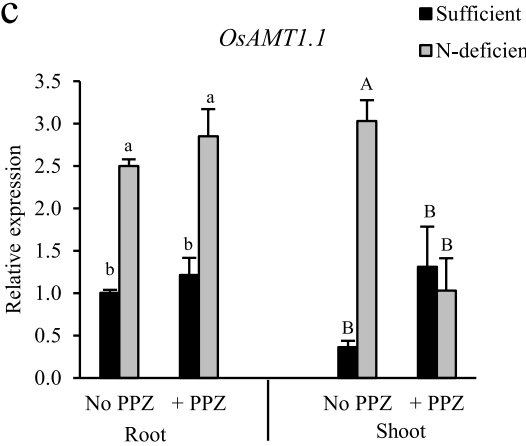

d

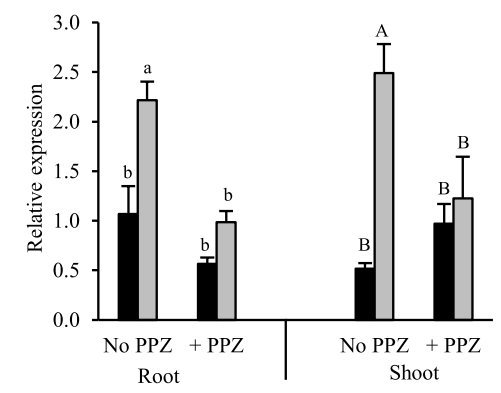

$\mathrm{e}$

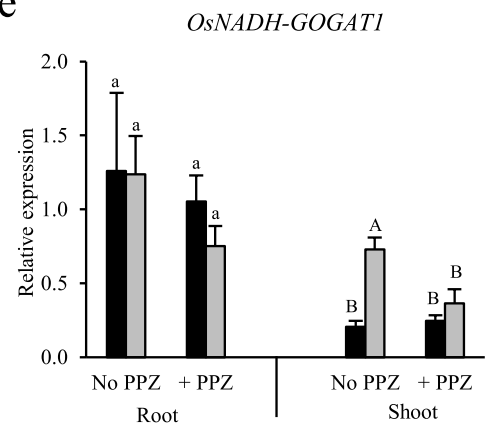

Fig. 4 Gene expression analyses of $\mathrm{N}$ deficiency-responsive genes in roots and shoots of rice seedlings grown in the absence and presence of PPZ and subjected to sufficient or N-deficient condition. Relative expression levels were normalized with OSACTIN. Data are means \pm SE $(n=3)$. Different letters indicate significant differences $(p<0.05)$ according to Duncan's multiple range test (DMRT) (lowercase for root data; uppercase for shoot data).

whether PPZ treatment affects expression of these genes under $\mathrm{N}$ deficiency, transcript levels in shoots and roots were measured by quantitative RT-PCR. It was found that expressions of these genes in PPZ-untreated plants were significantly upregulated under $\mathrm{N}$-deficient condition. However, the degrees of upregulation were attenuated by PPZ treatment (Fig. 4). In particular, when PPZ was not applied, OsNRT2.1 in roots was dramatically induced by $\mathrm{N}$ deficiency (Fig. 4a), but its expression in shoots was not detectable, which is consistent with previous reports that this gene is strongly inducible in roots by $\mathrm{N}$ deficiency [34]. These results suggest that PPZ treatment could attenuate the N-deficiencyinduced transcriptional response. In contrast, the attenuation effect was not observed in N-deficiencyinduced OsAMT1.1 expression in the root (Fig. 4c). This might be due to distinct expression patterns of different members of AMT1 gene family and their regulation by $\mathrm{BR}$, as suggested by works in
Arabidopsis that AMT1 expression is controlled by a complex interaction between nutrient and hormone signaling in plants [35].

Upon Pi deficiency, a MYB transcription factor PHOSPHATE STARVATION RESPONSE (PHR), which is the central regulator of the Pi signaling pathway, activates expression of the Pi starvationinduced (PSI) genes, such as INDUCED BY PHOSPHATE STARVATION 1 (IPS1) and SPX1, in response to Pi deficiency [36]. To determine whether PPZ treatment affects Pi signaling and the expression of PSI genes, expressions of five PSI genes: OsIPS1, OsSPX1, OSSQD2 (SULFOQUINOVOSYLDIACYLGLYCEROL 2), OSPAP1O (PURPLE ACID PHOSPHATASE 10), and OSPT8 (PHOSPHATE TRANSPORTER 8), were investigated in rice seedlings grown under Pisufficient and Pi-deficient conditions in the presence and absence of PPZ. Their expression in roots showed dramatic upregulation by Pi deficiency, and such response was suppressed by PPZ treatment 

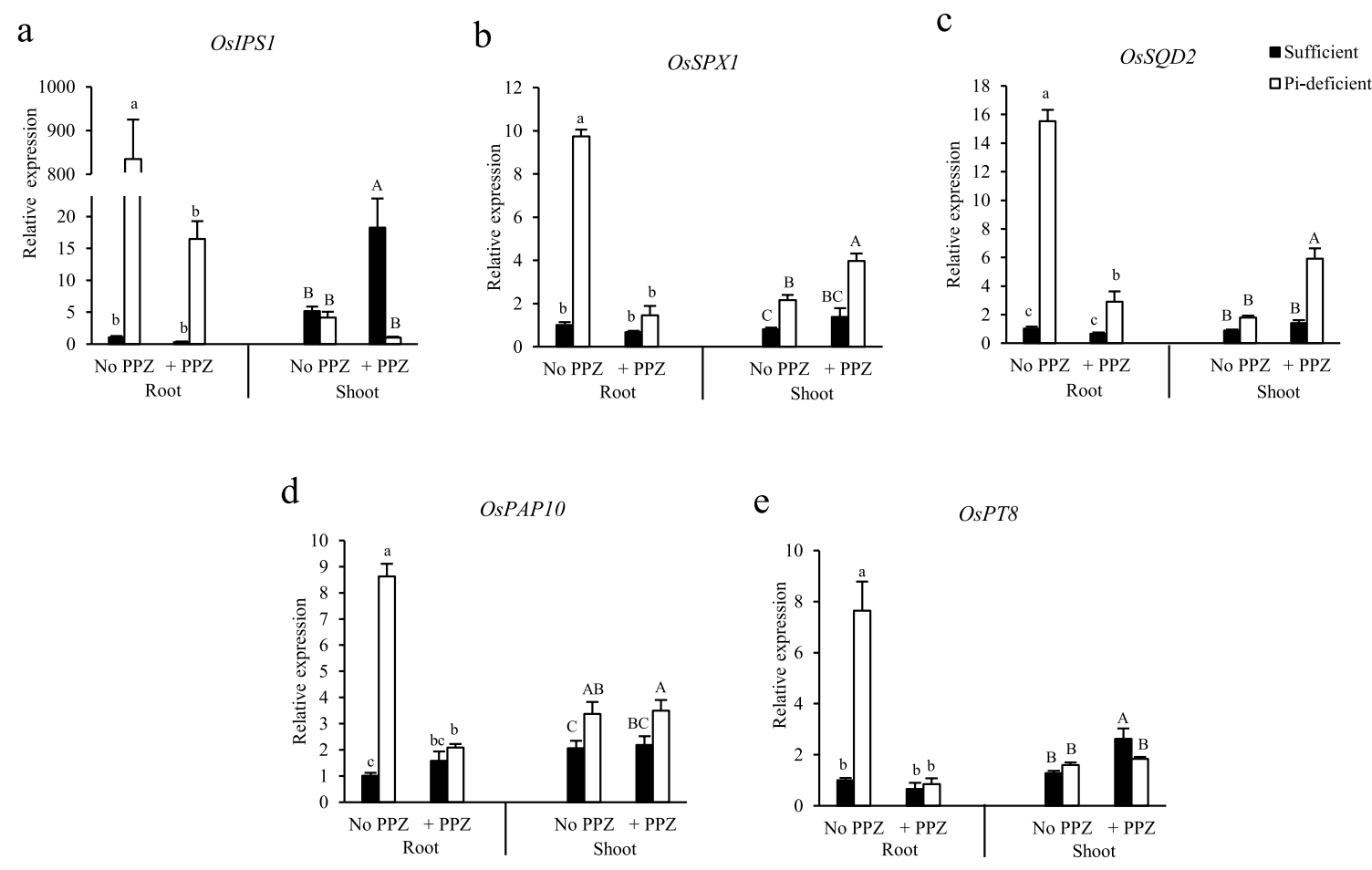

Fig. 5 Gene expression analyses of Pi deficiency-responsive genes in roots and shoots of rice seedlings grown in the absence and presence of PPZ and subjected to sufficient or Pi-deficient condition. Relative expression levels were normalized with OsACTIN. Data are means \pm SE $(n=3)$. Different letters indicate significant differences $(p<0.05)$ according to Duncan's multiple range test (DMRT) (lowercase for root data; uppercase for shoot data).

(Fig. 5). PPZ treatment, however, enhanced responses of OsSQD2 expression in shoots in response to Pi deficiency (Fig. 5c). We also found that expressions of OsSPX1 and OsPAP1O in shoots was moderately induced by Pi deficiency under both PPZ-treated and untreated conditions (Fig. 5bd).

Under Pi-sufficient conditions, PPZ treatment did not significantly alter expression of the PSI genes with the exception of OSIPS1 and OsPT8 expression in shoots that showed significant upregulation by PPZ (Fig. 5a-e). Interestingly, PPZ treatment significantly reduced expression of OSIPS1 in shoots under Pi-deficient conditions (Fig. 5a). Together, these expression analyses demonstrated an interesting trend that PPZ treatment suppressed upregulation of PSI genes, especially in roots.

Our gene expression analysis results showed that PPZ treatment reduced levels of $\mathrm{N}$ and $\mathrm{Pi}$ deficiency-responsive gene expressions (Figs. 4 and 5). Previous studies have shown that PPZ treatments could block nuclear localization of the BR- regulated transcription factors BRASSINAZOLE RESISTANT1 (BZR1) in Arabidopsis, and thus inhibiting the BR-regulated transcriptional regulation [17]. Furthermore, direct targets of BZR1 and BES1/BZR2 transcription factors in Arabidopsis have been determined by chromatin immunoprecipitation assays (ChIP) followed by microarray (ChIP-chip) or sequencing (ChIP-seq), and the results revealed thousands of target genes involved in various physiological responses [37-39]. These include genes encoding nitrate transporters (AtNRT1.1, AtNRT1.2, AtNRT1.7, AtNRT1.8, AtNRT2.2, AtNRT2.6, and AtNRT2.7); ammonium transporters (AtAMT1;1, AtAMT1;2, and AtAMT2); phosphate transporters (AtPHT4;1 and AtPHT4;2); purple acid phosphatases (AtPAP19, AtPAP28 and AtPAP29); and SPX proteins (AtSPX1 and AtSPX2). Such findings suggest that expression of target genes might be BR dependent, and the PPZ treatment could interfere their transcriptional regulation by nutrient deficiency. In agreement, recent studies found 
that brassinazole treatment reduced expression of several NRT1 genes in cucumber under suboptimal root zone temperature when compared with 24epibrassinolide treatments [40].

Our results showed that expression of $\mathrm{N}$ and $\mathrm{Pi}$ deficiency-responsive genes was attenuated by PPZ, although PPZ-treated plants did not have lower total $\mathrm{N}$ and $\mathrm{P}$ contents when compared to the untreated plants (Fig. 3). This may be due to the experimental conditions, which were performed in closed hydroponic containers. In such limited conditions, plants cannot acquire more of the nutrients despite upregulating expression of relevant transporters and enzymes. Future experiments conducted in soil condition would be necessary for a better understanding on plant adaptation to nutrient deficiency.

\section{CONCLUSION}

This study demonstrated that $\mathrm{N}$ and Pi deficiencies induced expression of BR biosynthesis genes. Direct quantification of endogenous $\mathrm{BR}$ will be needed to confirm whether $\mathrm{N}$ - and Pi-deficient plants produced more endogenous BR. Our studies supported putative roles of $\mathrm{BR}$ on nutrient deficiency stress in rice and illustrated the impact of BR biosynthesis inhibition in attenuating plant responses to nutrient deficiency. Hence, heavy repeated application of PPZ to control fungal diseases in rice paddy field could perhaps interfere plant adaptation in nutrientlimited environment.

\section{APPENDIX A. SUPPLEMENTARY DATA}

Supplementary data associated with this article can be found at http://dx.doi.org/10.2306/ scienceasia1513-1874.2021.S011.

Acknowledgements: This work was funded by Research Grant for New Scholar Ratchadaphiseksomphot Endowment Fund Chulalongkorn University (RGN_2559_032_11_23) to J.C., FAFU Distinguished Young Scholars (XJQ201707) and Fujian General program (2016J01098) to W.W., Science Achievement Scholarship of Thailand (SAST) scholarship to K.J., the Royal Golden Jubilee (RGJ) PhD scholarship to S.P., and $\mathrm{K}+\mathrm{S}$ Group scholarship to L.Z. The authors would like to thank Zhichang Chen (FAFU) for assistance with total $\mathrm{N}$ and $\mathrm{P}$ measurement.

\section{REFERENCES}

1. Xu G, Fan X, Miller AJ (2012) Plant nitrogen assimilation and use efficiency. Annu Rev Plant Biol 63, 153-182.
2. López-Arredondo DL, Leyva-González MA, GonzálezMorales SI, López-Bucio J, Herrera-Estrella L (2014) Phosphate nutrition: improving low-phosphate tolerance in crops. Annu Rev Plant Biol 65, 95-123.

3. Rogers ED, Benfey PN (2015) Regulation of plant root system architecture: implications for crop advancement. Curr Opin Biotechnol 32, 93-98.

4. Ogawa S, Selvaraj MG, Fernando AJ, Lorieux M, Ishitani M, McCouch S, Arbelaez (2014) N- and Pmediated seminal root elongation response in rice seedlings. Plant Soil 375, 303-315.

5. Klinnawee L, Noirungsee N, Nopphakat K, Runsaeng P, Chantarachot $\mathrm{T}$ (2021) Flooding overshadows phosphorus availability in controlling the intensity of arbuscular mycorrhizal colonization in Sangyod Muang Phatthalung lowland indica rice. ScienceAsia 47, 202-210.

6. Chaiwanon J, Wang W, Zhu JY, Oh E, Wang ZY (2016) Information integration and communication in plant growth regulation. Cell 164, 1257-1268.

7. Zhu JY, Sae-Seaw J, Wang ZY (2013) Brassinosteroid signalling. Development 140, 1615-1620.

8. Nolan TM, Vukašinović N, Liu D, Russinova E, Yin Y (2020) Brassinosteroids: multidimensional regulators of plant growth, development, and stress responses. Plant Cell 32, 295-318.

9. Pandey A, Devi LL, Singh AP (2020) Review: Emerging roles of brassinosteroid in nutrient foraging. Plant Sci 296, ID 110474.

10. Jia Z, Giehl RFH, von Wirén N (2020) The root foraging response under low nitrogen depends on DWARF1-mediated brassinosteroid biosynthesis. Plant Physiol 183, 998-1010.

11. Qin L, Walk TC, Han P, Chen L, Zhang S, Li Y, Hu X, Xie L, et al (2019) Adaption of roots to nitrogen deficiency revealed by 3D quantification and proteomic analysis. Plant Physiol 17, 329-347.

12. Singh AP, Fridman Y, Friedlander-Shani L, Tarkowska D, Strnad M, Savaldi-Goldstein S (2014) Activity of the brassinosteroid transcription factors BRASSINAZOLE RESISTANT1 and BRASSINOSTEROID INSENSITIVE1-ETHYL METHANESULFONATE- SUPPRESSOR1/BRASSINAZOLE RESISTANT2 blocks developmental reprogramming in response to low phosphate availability. Plant Physiol 166, 678-688.

13. Jiao X, Wang H, Yan J, Kong X, Liu Y, Chu J, Chen X, Fang R, et al (2020) Promotion of BR biosynthesis by miR444 is required for ammonium-triggered inhibition of root growth. Plant Physiol 182, 1454-1466.

14. Zou L, Qu M, Zeng L, Xiong G (2020) The molecular basis of the interaction between brassinosteroid induced and phosphorous deficiency induced leaf inclination in rice. Plant Growth Regul 91, 263-276.

15. Khunpona B, Cha-umb S, Faiyuec B, Uthaibutraa J, Saengnila K (2017) Influence of paclobutrazol on growth performance, photosynthetic pigments, and antioxidant efficiency of Pathumthani 1 rice 
seedlings grown under salt stress. ScienceAsia 43, 70-81.

16. Oh K, Matsumoto T, Hoshi T, Yoshizawa Y (2016) In vitro and in vivo evidence for the inhibition of brassinosteroid synthesis by propiconazole through interference with side chain hydroxylation. Plant Signal Behav 11, e1158372.

17. Chaiwanon J, Wang ZY (2015) Spatiotemporal brassinosteroid signaling and antagonism with auxin pattern stem cell dynamics in Arabidopsis roots. Curr Biol 25, 1031-1042.

18. Hartwig T, Corvalan C, Best NB, Budka JS, Zhu JY, Choe S, Schulz B (2012) Propiconazole is a specific and accessible brassinosteroid (BR) biosynthesis inhibitor for arabidopsis and maize. PLoS One 7, e36625.

19. Song L, Chen W, Yao Q, Guo B, Valliyodan B, Wang Z, Nguyen HT (2019) Genome-wide transcriptional profiling for elucidating the effects of brassinosteroids on Glycine max during early vegetative development. Sci Rep 9, ID 16085.

20. Corvalán C, Choe S (2017) Identification of brassinosteroid genes in Brachypodium distachyon. BMC Plant Biol 17, ID 5.

21. Blandino M, Galeazzi M, Savoia W, Reyneri A (2012) Timing of azoxystrobin+propiconazole application on maize to control northern corn leaf blight and maximize grain yield. Field Crops Res 139, 20-29.

22. Edwards PG, Murphy TM, Lydy MJ (2016) Fate and transport of agriculturally applied fungicidal compounds, azoxystrobin and propiconazole. Chemosphere 146, 450-457.

23. Kim IS, Beaudette LA, Shim JH, Trevors JT, Suh YT (2002) Environmental fate of the triazole fungicide propiconazole in a rice-paddy-soil lysimeter. Plant Soil 239, 321-331.

24. Yoshida S (1976) Routine procedure for growing rice plants in culture solution. Laboratory Manual for Physiological Studies of Rice, 61-67.

25. Hong Z, Ueguchi-Tanaka M, Umemura K, Uozu S, Fujioka S, Takatsuto S, Yoshida S, Ashikari M, et al (2003) A rice brassinosteroid-deficient mutant, ebisu dwarf (d2), is caused by a loss of function of a new member of cytochrome P450. Plant Cell 15, 2900-2910.

26. Morinaka Y, Sakamoto T, Inukai Y, Agetsuma M, Kitano H, Ashikari M, Matsuoka M (2006) Morphological alteration caused by brassinosteroid insensitivity increases the biomass and grain production of rice. Plant Physiol 141, 924-931.

27. Best NB, Johal G, Dilkes BP (2017) Phytohormone inhibitor treatments phenocopy brassinosteroidgibberellin dwarf mutant interactions in maize. Plant Direct 1, 1-18.
28. Vriet C, Russinova E, Reuzeau C (2013) From squalene to brassinolide: the steroid metabolic and signaling pathways across the plant kingdom. Mol Plant 6, 1738-1757.

29. Chung Y, Choe S (2013) The regulation of brassinosteroid biosynthesis in arabidopsis. CRC Crit Rev Plant Sci 32, 396-410.

30. Wang Z, Rahman AM, Wang G, Ludewig U, Shen J, Neumann G (2015) Hormonal interactions during cluster-root development in phosphate-deficient white lupin (Lupinus albus L.). J Plant Physiol 177, 74-82.

31. Song L, Chen W, Yao Q, Guo B, Valliyodan B, Wang Z, Nguyen HT (2019) Genome-wide transcriptional profiling for elucidating the effects of brassinosteroids on Glycine max during early vegetative development. Sci Rep 9, ID 16085.

32. Wang B, Li G, Zhang WH (2015) Brassinosteroids are involved in Fe homeostasis in rice (Oryza sativa L.). $J$ Exp Bot 66, 2749-2761.

33. Yang W, Yoon J, Choi H, Fan Y, Chen R, An G (2015) Transcriptome analysis of nitrogen-starvationresponsive genes in rice. BMC Plant Biol 15, ID 31.

34. Araki R, Hasegawa H (2006) Expression of rice (Oryza sativa L.) genes involved in high-affinity nitrate transport during the period of nitrate induction. Breed Sci 56, 295-302.

35. Zhao BT, Zhu XF, Jung JH, Xuan YH (2016) Effect of brassinosteroids on ammonium uptake via regulation of ammonium transporter and N-metabolism genes in Arabidopsis. Biol plant 60, 563-571.

36. Bustos R, Castrillo G, Linhares F, Puga MI, Rubio V, Pérez-Pérez J, Solano R, Leyva A, et al (2010) A central regulatory system largely controls transcriptional activation and repression responses to phosphate starvation in Arabidopsis. PLoS Genet 6, e1001102.

37. Sun Y, Fan XY, Cao DM, Tang W, He K, Zhu JY, He JX, Bai MY, et al (2010) Integration of brassinosteroid signal transduction with the transcription network for plant growth regulation in Arabidopsis. Dev Cell 19, 765-77.

38. Oh E, Zhu JY, Bai MY, Arenhart RA, Sun Y, Wang ZY (2014) Cell elongation is regulated through a central circuit of interacting transcription factors in the Arabidopsis hypocotyl. eLife 3, e03031.

39. Yu X, Li L, Zola J, Aluru M, Ye H, Foudree A, Gui $\mathrm{H}$, Anderson S, et al (2011) A brassinosteroid transcriptional network revealed by genome-wide identification of BESI target genes in Arabidopsis thaliana. Plant J 65, 634-646.

40. Anwar A, Li Y, He C, Yu X (2019) 24-Epibrassinolide promotes $\mathrm{NO}_{3}^{-}$And $\mathrm{NH}_{4}^{+}$ion flux rate and NRT1 gene expression in cucumber under suboptimal root zone temperature. BMC Plant Biol 19, ID 453. 


\section{Appendix A. Supplementary data}

Table S1 Gene specific primers used in this study.

\begin{tabular}{|c|c|c|}
\hline Gene & Sequence & Reference \\
\hline OsNRT1.1 & $\begin{array}{l}\text { F: CCTCGCAAGTGACCCTTGAAT } \\
\text { R: CGATGGCTAATGAGGAACCCTT }\end{array}$ & {$[1]$} \\
\hline OsNRT2.1 & $\begin{array}{l}\text { F: TTCGCGAACCCGCATATGA } \\
\text { R: GTTGAGGTTGTCGCGGATGAT }\end{array}$ & {$[1]$} \\
\hline OsAMT1.1 & $\begin{array}{l}\text { F: GGTTTCTCTCCCTCTCCGAT } \\
\text { R: CCACCTTCACACCACACATT }\end{array}$ & {$[2]$} \\
\hline OsGS1.1 & $\begin{array}{l}\text { F: GAGTCGTCGTCTCATTTGACCC } \\
\text { R: GTAGCCACCATCGTTCCTCATC }\end{array}$ & {$[1]$} \\
\hline OsNADH-GOGAT1 & $\begin{array}{l}\text { F: TGCTTGAGAGAATGGCGCA } \\
\text { R: AACCCAGCATCCTTTGTCACC }\end{array}$ & {$[1]$} \\
\hline OsIPS1 & $\begin{array}{l}\text { F: AAGGGCAGGGCACACTCCACATTA } \\
\text { R: ATTAGAGCAAGGACCGAAACACA }\end{array}$ & {$[3]$} \\
\hline OsSPX1 & $\begin{array}{l}\text { F: GACCAGCTTCTACCATCAAACG } \\
\text { R: AGTTCCTGCTGCTCCTCTGG }\end{array}$ & {$[4]$} \\
\hline OsSQD2 & $\begin{array}{l}\text { F: CTGAAAACGGTAATGGATAGG } \\
\text { R: AACAACAACAGCACGAGC }\end{array}$ & {$[5]$} \\
\hline OsPAP10 & $\begin{array}{l}\text { F: ATACTGGCAGCCGACGGATGA } \\
\text { R: GAGGGAGCTGGAGCGGAGAA }\end{array}$ & {$[5]$} \\
\hline OsPT8 & $\begin{array}{l}\text { F: AGAAGGCAAAAGAAATGTGTGTTAAAT } \\
\text { R: AAAATGTATTCGTGCCAAATTGCT }\end{array}$ & {$[6]$} \\
\hline OsCYP85A1 & $\begin{array}{l}\text { F: TGATCCATTCCTGTACCCTG } \\
\text { R: TACCTTCTTCCTCCCATCTG }\end{array}$ & {$[7]$} \\
\hline OsDWF4 & $\begin{array}{l}\text { F: AGTCGCGTGCTGCCATTCTCGGAG } \\
\text { R: AGCAAGCTCAGCAAGAGGTCCAGG }\end{array}$ & {$[8]$} \\
\hline OsD2 & $\begin{array}{l}\text { F: AGCTGCCTGGCACTAGGCTCTACAGATCAC } \\
\text { R: ATGTTGTCGGAGATGAGCTCGTCGGTGAGC }\end{array}$ & [9] \\
\hline OsACTIN1 & $\begin{array}{l}\text { F: TGCTATGTACGTCGCCATCCAG } \\
\text { R: AATGAGTAACCACGCTCCGTCA }\end{array}$ & {$[10]$} \\
\hline
\end{tabular}

\section{REFERENCES}

1. Liang Z, Bao A, Li H, Cai H (2015) The effect of nitrogen level on rice growth, carbon-nitrogen metabolism and gene expression. Biologia 70, 1340-1350.

2. Sun H, Qian Q, Wu K, Luo J, Wang S, Zhang C, Ma Y, Liu Q, et al (2014) Heterotrimeric G proteins regulate nitrogen-use efficiency in rice. Nat Genet 46, 652-656.

3. Shen C, Yue R, Yang Y, Zhang L, Sun T, Tie S, Wang H (2014) OsARF16 is involved in cytokinin-mediated inhibition of phosphate transport and phosphate signaling in rice (Oryza sativa L). PLoS One 9, 3-12.

4. Ye Y, Yuan J, Chang X, Yang M, Zhang L, Lu K, Lian X (2015) The phosphate transporter gene OsPht1;4 is involved in phosphate homeostasis in rice. PLoS One 10, 1-15.

5. Pei W, Jain A, Sun Y, Zhang Z, Ai H, Liu X, Wang H, Feng B, et al (2017) OsSIZ2 exerts regulatory influences on the developmental responses and phosphate homeostasis in rice. Sci Rep 7, 1-13.

6. Zhu XF, Zhu CQ, Zhao XS, Zheng SJ, Shen RF (2016) Ethylene is involved in root phosphorus remobilization in rice (Oryza sativa) by regulating cell-wall pectin and enhancing phosphate translocation to shoots. Ann Bot 118, 645-653.

7. Sakamoto T, Kitano H, Fujioka S (2013) Genetic background influences brassinosteroid-related mutant phenotypes in rice. Am J Plant Sci 4, 211-220.

8. Wu Q, Li D, Li D, Liu X, Zhao X, Li X, Li S, Zhu L (2015) Overexpression of OsDof12 affects plant architecture in rice (Oryza sativa L.). Front Plant Sci 6, 1-11.

9. Tong H, Liu L, Jin Y, Du L, Yin Y, Qian Q, Zhu L, Chu C (2012) DWARF AND LOW-TILLERING Acts as a direct downstream target of a GSK3/SHAGGY-like kinase to mediate brassinosteroid responses in rice. Plant Cell 24, 2562-2577.

10. Zhang H, Wu K, Wang Y, Peng Y, Hu F, Wen L, Han B, Qian Q, et al (2012) A WUSCHEL-like homeobox gene, OsWOX3B responses to NUDA/GL-1 locus in rice. Rice 5, 1-10. 